\title{
PREFACE: “ADVANCED ENERGETIC MATERIALS AND TECHNIQUES FOR ROCKET PROPULSION" IN HONOR OF PROF. KENNETH KUAN-YUN KUO
}

This Special Issue of the International Journal of Energetic Materials and Chemical Propulsion (IJEMCP) is the first of a sequel of three Memorial Issues meant to honor Professor Kenneth (Ken) Kuan-Yun Kuo, founder and editor-in-chief of IJEMCP, who passed away on July 31, 2016. The co-editors considered it appropriate to open this issue with a paper, unpublished in the open literature, by Ken and his former students, Dr. Heath T. Martin and Dr. Andrew C. Cortopassi. The original paper was modified and downgraded to public release thanks to the cooperation of the NASA security office; it proudly shows another great technical achievement by Ken and his research team at Pennsylvania State University (PSU).

All memorial issues will include six papers, and this 1st Memorial Issue also makes room for a special section Thanks for the Memories fully dedicated to the person of Ken (as detailed hereunder). To stress the vast scope and the worldwide influence of Ken's professional activities, in addition to the opening paper by Ken and his coworkers, five papers were selected for publication from different countries carrying out advanced research activities in energetic materials and chemical propulsion:

1. Valery A. Babuk and Alexander A. Nizyaev, Russia, about smoke oxide particle formation from aluminized propellants.

2. Inna Zamir, Dan Grinstein, and Alon Gany, Israel, about electric effects on the burning rate of ammonium nitrate-based solid propellants.

3. Yue Tang, Suhang Chen, Wei Zhang, Ruiqi Shen, Luigi T. DeLuca, and Yinghua Ye, China and Italy, about energetic particle-embedded paraffin-based fuels for hybrid rocket propulsion.

4. Siva Kumar Valluri, Ian Monk, Mirko Schoenitz, and Edward Dreizin, USA and Russia, about fuel-rich aluminum-metal fluoride thermites.

5. Volker Gettwert, Andrea Franzin, Manfred A. Bohn, Luigi T. DeLuca, Thomas Heintz, and Volker Weiser, Germany and Italy, about ADN/GAP composite propellants with and without metallic fuels.

Ken was born in Kunming, Southern China, and conducted his initial studies in Taiwan, where he graduated with a BS degree from the National Taiwan University in 1961. After moving to the U.S., Ken received a MS in mechanical engineering from the University of California at Berkeley in 1964. He worked as a design engineer at Garrett AiResearch from 1964 to 1968 before continuing his studies. Finally, Ken obtained a PhD from the Department of Aerospace and Mechanical Sciences of Princeton University, Princeton, New Jersey, under the guidance of Professor Martin Summerfield, one of the pioneers of rocket propulsion in the U.S. In 1971, he 
submitted his doctoral thesis entitled, "Theory of flame front propagation in porous propellant charges under confinement."

In 1972, Ken moved to PSU, where he founded the High-Pressure Combustion Lab and started his exceptional professional career, which continued until his last days. Ken authored four books, edited 11 volumes, and published about 500 papers in the broad areas of combustion and energetic materials. Moreover, he directed about 100 scientific research projects and supervised hundreds of students, including $40 \mathrm{PhD}$ candidates. Finally, Ken founded the International Symposium on Special Topics in Chemical Propulsion in 1988, with the first symposium being held in Athens, Greece, and the last one at Poitiers, France, in 2014.

A full obituary was published in 2016 in volume 15, issue 4 of this journal, pages v-vii. Instead of celebrating the many accomplishments of Ken along his extraordinary and very long professional life, in this first Memorial Issue the co-editors preferred to illustrate the inception of his phenomenal success starting from Princeton University. A vivid and captivating portrait of Ken at the very beginning of his academic career was compiled by Dr. Leonard H. Caveny, for years a very close coworker of Professor Summerfield at the Guggenheim Aerospace Lab of Princeton University. In addition, several of his former colleagues, as either students or young professionals, at Guggenheim provided short snapshots of the young Ken as remembered from the years at Princeton University (1968-1972). Further short reminiscences were offered by international colleagues who met and became familiar with Ken from all over the world. Altogether, this additional section of the issue is called Thanks for the Memories, as suggested by one of the strongest supporters of this editorial initiative (Bernard M. Kosowski, MACH I, USA).

This photo shows the recent dedication to Ken of the High-Pressure Combustion Laboratory at Penn State, May 2017. A full gallery of photos in Ken's life and career, provided by friends and colleagues, will be published in the next Memorial Issue.

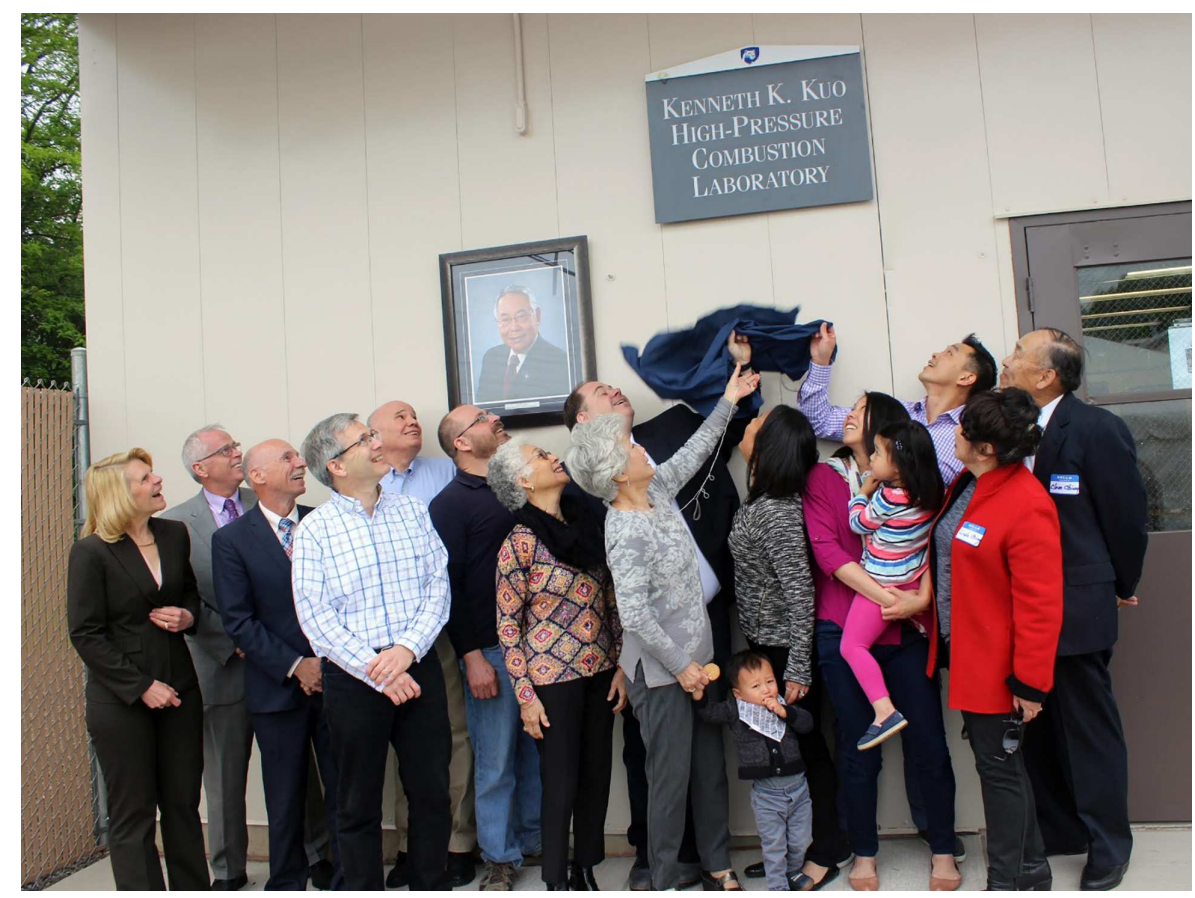


Our goal for this Special Issue is to honor Ken in the first anniversary of his death. His rigorous approach, care for details, and hard work made him an example for all of us. A year ago, we lost a colleague, a friend, a mentor who every day showed us the right way to go with his own example. In many respects, Ken was great and unique; many will follow his traces, but nobody will replace him!

Guest Editors:

Luigi T. DeLuca

Italy

Keiichi Hori

Japan

John F. Zevenbergen

Netherlands

Volume 16, Issue 1, 2017 